\title{
Assessment of the anterior segment and intraocular pressure changes after phacoemulsification
}

\section{Evaluación del segmento anterior y cambios en la presión intraocular después de la cirugía de catarata por facoemulsificación}

\author{
Adem Ugurlu* and Nurdan Gamze-Tasli \\ Department of Ophthalmology, Faculty of Medicine, Erzincan Binali Yildirim University, Erzincan, Turkey
}

\begin{abstract}
Aim: The aim of the study was to investigate the changes in anterior segment parameters and intraocular pressure (IOP) after uneventful phacoemulsification. Methods: $A$ total of 118 patients who underwent uneventful phacoemulsification and intraocular lens implantation were included in the study. The patients underwent a detailed ophthalmologic examination including best-corrected visual acuity, slit-lamp biomicroscopy, gonioscopy, fundoscopy, IOP measurement, and anterior segment evaluation at baseline (preoperatively) and 1 week, 1,3 , and 6 months, as well as 1 year after surgery. Results: Fifty-nine patients were male and 59 were female. The mean age was $64.9 \pm 10.8(25-89)$ years. Mean IOP at baseline was $16.9 \pm$ $1.9(11-20) \mathrm{mmHg}$. Mean IOP was $12.9 \pm 1.8(10-18) \mathrm{mmHg} 1$ year after surgery $(p<0.001)$. Mean anterior chamber depth $(A C D)$ was $2.50 \pm 0.35(1.71-3.45) \mathrm{mm}$ at baseline and $3.98 \pm 0.40(2.98-4.60) \mathrm{mm} 1$ year after surgery $(p<0.001)$. Mean anterior chamber angle (ACA) was $33.06 \pm 3.91$ (29.7-45) degrees at baseline and $38.6 \pm 4.8$ (32.2-50.2) degrees 1 year after surgery $(p<0.001)$. Conclusions: This study showed that an IOP decrease. Other findings such as ACD, ACA, and anterior chamber volume increased in the short- and long-term follow-up after phacoemulsification.
\end{abstract}

Key words: Assessment. Anterior segment. Intraocular pressure. Phacoemulsification.

\section{Resumen}

Objetivo: Investigar los cambios en los parámetros del segmento anterior y los valores de presión intraocular después de una cirugía de facoemulsificación sin complicaciones. Métodos: Se incluyeron en el estudio un total de 118 pacientes que se sometieron a cirugía de catarata por facoemulsificación sin incidentes con implantación de lente intraocular. Los pacientes se sometieron a un examen oftalmológico detallado que incluyó agudeza visual mejor corregida, biomicroscopia con lámpara de hendidura, gonioscopia, fundoscopia, medición de la presión intraocular (PIO) y evaluación del segmento anterior en la basal (preoperatoriamente), la primera semana, los meses primero, tercero y sexto, y el primer año después de la cirugía. Resultados: Cincuenta y nueve pacientes eran hombres y cincuenta y nueve mujeres. La edad media de los pacientes fue de $64.9 \pm 10.8$ (25-89) años. La PIO media fue de $16.9 \pm 1.9$ (11-20) $\mathrm{mmHg}$ en la basal y de $12.9 \pm 1.8$ $(10-18) \mathrm{mmHg}$ el primer año después de la cirugía $(p<0.001)$. La profundidad media de la cámara anterior fue de $2.50 \pm$ $0.35(1.71-3.45) \mathrm{mm}$ en la basal y de $3.98 \pm 0.40(2.98-4.60) \mathrm{mm}$ al primer año postoperatorio $(p<0.001)$. El ángulo medio

\section{Correspondence:}

*Adem Ugurlu

Department of Ophthalmology, Faculty of Medicine

Basbaglar Mh. 1429 Sk 2/1

Date of reception: 24-04-2020

Date of acceptance: $25-06-2020$

DOI: 10.24875/RMOE.M20000129
Available online: $09-11-2020$ Rev Mex Oftalmol (Eng). 2020;94(6):228-235

www.rmo.com.mx

E-mail: ademugurlu88@ hotmail.com

Published by Permanyer. This is an open access article under the CC BY-NC-ND license 2604-1731/@ 2020 Sociedad Mexicana de Oftalm
(http://creativecommons.org/licenses/by-nc-nd/4.0/). 
de la cámara anterior fue de $33.06 \pm 3.91$ (29.7-45) grados en la basal del estudio y de $38.6 \pm 4.8$ (32.2-50.2) grados al primer año postoperatorio $(p<0.001)$. Conclusiones: Este estudio mostró que la PIO disminuyó, pero otros hallazgos, como la profundidad de la cámara anterior, el ángulo de la cámara anterior y el volumen de la cámara anterior, aumentaron en el seguimiento a corto y largo plazo después de la cirugía de facoemulsificación.

Palabras clave: Evaluación. Segmento anterior. Presión intraocular. Facoemulsificación.

\section{Background}

A cataract is a condition characterized by the opacification and loss of transparency of the crystalline lens. There are several reasons for cataract development ${ }^{1-3}$. Cataracts are often acquired but rarely congenital ${ }^{4-6}$. The treatment of cataracts is surgery, and phacoemulsification is the most widely used surgical method to treat this ocular disorder ${ }^{6-8}$. Decreased visual acuity is one of the main indications for phacoemulsification $2,6,7$.

Phacoemulsification and intraocular lens (IOL) implantation can cause alterations of intraocular parameters. In particular, they cause an increase of anterior chamber depth (ACD), anterior chamber angle (ACA), and anterior chamber volume $(\mathrm{ACV})^{9-15}$. The age-related thickening of the human lens induces many structural alterations related to the outflow pathway that may lead to an increase of intraocular pressure (IOP), associated with glaucoma. Many studies have investigated the mechanisms of reduced IOP after phacoemulsification by measuring the post-operative changes in anterior segment biometric parameters to maintain access for aqueous outflow ${ }^{16-18}$.

Modern cataract surgery results in IOP reduction $^{8,9,16-19}$. As a result of the extraction of the natural lens and implantation of an IOL, which is thinner than the natural lens, the volume and depth of the anterior chamber increase, the iridocorneal angle widens, and the iris moves backwards ${ }^{20}$. At the same time, endogenous prostaglandin F2 secretion, an inflammatory mediator, is elevated due to surgical trauma, leading to an increase of aqueous humor uveoscleral outflow ${ }^{21}$.

Although there is substantial research on short-term changes in IOP and anterior segment parameters after uneventful cataract surgery, there are not many clinical studies evaluating long-term changes. This prospective study is one of the few studies in which both IOP and detailed anterior segment parameters were evaluated both before and after phacoemulsification over a 1-year period.

In this prospective research, the alterations in anterior segment parameters and IOP values were investigated after uneventful phacoemulsification over a 1-year follow-up period.

\section{Methods}

Between November 2017 and May 2018, 118 eyes of 118 patients who underwent uncomplicated phacoemulsification and foldable IOL implantation with a diagnosis of cataract in Erzincan Binali Yildirim University Faculty of Medicine Ophthalmology Clinic were included in the study. The study was conducted in accordance with the principles of the Declaration of Helsinki, and informed consent was obtained from each patient before the study. The Institutional Ethics Committee of the Erzincan Binali Yildirim University also approved the study (Number of ethical board decision: 33216249-804.01-E.13165).

\section{Clinical evaluation}

Patients underwent a detailed ocular examination, including best-corrected visual acuity, slit-lamp biomicroscopy, gonioscopy, fundoscopy, IOP measurement, and anterior segment evaluation at baseline (preoperatively) and 1 week, 1, 3, and 6 months, as well as 1 year after phacoemulsification. IOP measurement was repeated 5 times a day (at 9:00, 11:00, 13:00, 15:00, 18:00), 1 day before surgery. Mean IOP value was calculated and noted as the baseline (pre-operative) IOP value. An angle evaluation was also performed using the Schaffer system, and none of the patients were grade 1 or 2 by gonioscopy.

Visual acuity was measured under photopic conditions using Snellen visual charts with the Nidek ophthalmic unit (Nidek Co., Ltd., Japan). The slit lamp biomicroscopic examination was performed using the Nidek Ophthalmic unit (Nidek Co., Ltd., Japan). Gonioscopic examination was undertaken using a Volk G-3 three-mirror glass goniofundus lens (Volk Optical, Inc., USA). Fundoscopic examination was made using $90 \mathrm{D}$ Volk lenses (Volk Optical, Inc., USA) under biomicroscopy. IOP measurements were performed with a Goldmann applanation tonometer (Haag-Streit, UK). All of the ocular examinations were carried out by the same clinician to avoid interobserver variation.

The depth, volume, and angle of the anterior chamber, central corneal thickness (CCT), and axial length were measured with an outpatient department scan-3 
Rev Mex Oftalmol (Eng). 2020;94(6)

Table 1. Intraocular pressure and anterior segment parameter changes before and after phacoemulsification

\begin{tabular}{|l|c|c|c|c|c|c|c|}
\hline & Before surgery & $\begin{array}{c}1 \text { week after } \\
\text { surgery }\end{array}$ & $\begin{array}{c}\text { 1 month after } \\
\text { surgery }\end{array}$ & $\begin{array}{c}3 \text { months after } \\
\text { surgery }\end{array}$ & $\begin{array}{c}6 \text { months after } \\
\text { surgery }\end{array}$ & $\begin{array}{c}\text { 1 year after } \\
\text { surgery }\end{array}$ & p value \\
\hline IOP & $16.9 \pm 1.9$ & $16.5 \pm 1.6$ & $13.9 \pm 1.7$ & $12.5 \pm 1.7$ & $12.7 \pm 1.6$ & $12.9 \pm 1.8$ & $<0.001$ \\
\hline ACD & $2.50 \pm 0.35$ & $3.96 \pm 0.39$ & $4.08 \pm 0.36$ & $4.11 \pm 0.34$ & $3.99 \pm 0.41$ & $3.98 \pm 0.40$ & $<0.001$ \\
\hline ANG & $33.06 \pm 3.91$ & $40.00 \pm 5.55$ & $40.16 \pm 5.43$ & $40.17 \pm 5.28$ & $39.1 \pm 4.92$ & $38.61 \pm 4.84$ & $<0.001$ \\
\hline ACV & $129.44 \pm 29.29$ & $173.61 \pm 25.78$ & $177.81 \pm 24.55$ & $179.21 \pm 23.90$ & $175.15 \pm 24.06$ & $174.70 \pm 26.01$ & $<0.001$ \\
\hline CCT & $548.78 \pm 42.13$ & $581.32 \pm 47.92$ & $556.98 \pm 41.92$ & $553.88 \pm 41.49$ & $550.81 \pm 42.19$ & $549.37 \pm 41.36$ & $<0.001$ \\
\hline
\end{tabular}

IOP: intraocular pressure; ACD: anterior chamber depth; ACA: anterior chamber angle; ACV: anterior chamber volume; CCT: Central corneal thickness.

topography device (Nidek Co., Ltd., Japan) in all patients before surgery. The measurements were repeated 1 week, 1, 3, 6, and 12 months postoperatively by the same staff member to avoid interobserver variation.

A 2.4-mm clear corneal incision was made in all cases by the same experienced surgeon, using the Infiniti vision system (Alcon, Inc.) with "stop and chop" or "chip and flip" phaco techniques in all patients. In all cases, phacoemulsification was completed successfully with capsular bag placement of an AcrySof IQ IOL (Alcon Laboratories, Inc.). The incisions were hydrated with balanced salt solution after viscoelastic removal (DisCoVisc Alcon Laboratories, Inc., Fort Worth, TX, USA). All patients were prescribed a topical antibiotic and steroid eye drops 4 times a day for 4 weeks after surgery.

\section{Exclusion criteria}

Patients with complications during phacoemulsification surgery, or those with a history of corneal disease, pseudoexfoliation, narrow angle, glaucoma, uveitis, previous ocular surgery or trauma, as well as posterior segment disorders, were excluded from the study. Patients with prolonged anterior chamber inflammation after phacoemulsification and those who needed to use steroid eye drops after 1-month post-surgery were also excluded from the study.

\section{Statistical analysis}

The Statistical Package for the Social Sciences version 22.0 (SPSS Inc., Chicago, IL, USA) was used for statistical analyses, and a $p<0.05$ was considered significant at the $95 \%$ confidence interval $(\mathrm{Cl})$. All data were expressed as mean, standard deviation, minimum, and maximum values. The Chi-squared test was used to compare nominal data. Pearson or Spearman tests were used for correlation analysis. The distribution of data was examined by the Kolmogorov-Smirnov test. An ANOVA or t-test was used to compare the normally distributed data while the Mann-Whitney $U$ and Kruskal-Wallis tests were used to compare data without normal distribution. The Friedman variance analysis and Wilcoxon test were used to compare recurrent measurements.

\section{Results}

In this research, 59 patients were male and 59 were female. The mean age of the participants was $64.9 \pm 10.8(25-89)$ years. The average axial length of the eyeball was $23.5 \pm 0.9(21.29-25.66) \mathrm{mm}$. IOP changes before and after surgery is shown in table 1 and figure 1.

There was no statistically significant difference between baseline and the 1-week post-operative measurement when IOP values were compared $(p=0.708)(95 \%$ $\mathrm{Cl}:-0.948$ to +1.722$)$. However, a statistically significant difference was observed between baseline and 1-, 3-, 6 -, and 12-month post-operative IOP values $(p<0.001)$ (95\% Cl: $0.618-1.422,1.957-2.818,1.681-2.605$, and 1.497-2.401, respectively). There was also a statistically significant difference between the post-operative $1^{\text {st }}$ week and the 1-, 3-, 6-, and 12-month IOP values ( $p$ < 0.001) (95\% Cl: 0.225-0.978, 1.561-2.378, 1.3822.144 , and 1.092-1.969, respectively). Similarly, a significant difference was observed between the post-operative $1^{\text {st }}$-month and the 3- and 6-month IOP measurements $(p<0.001)(95 \% \mathrm{Cl}: 0.937-1.798$ and 0.685-1.627, respectively). The post-operative $1^{\text {st }}$-month and $1^{\text {st }}$-year IOP measurements also significantly differed $(p=0.018)$ (95\% Cl: 0.428-1.231). However, there was no significant 


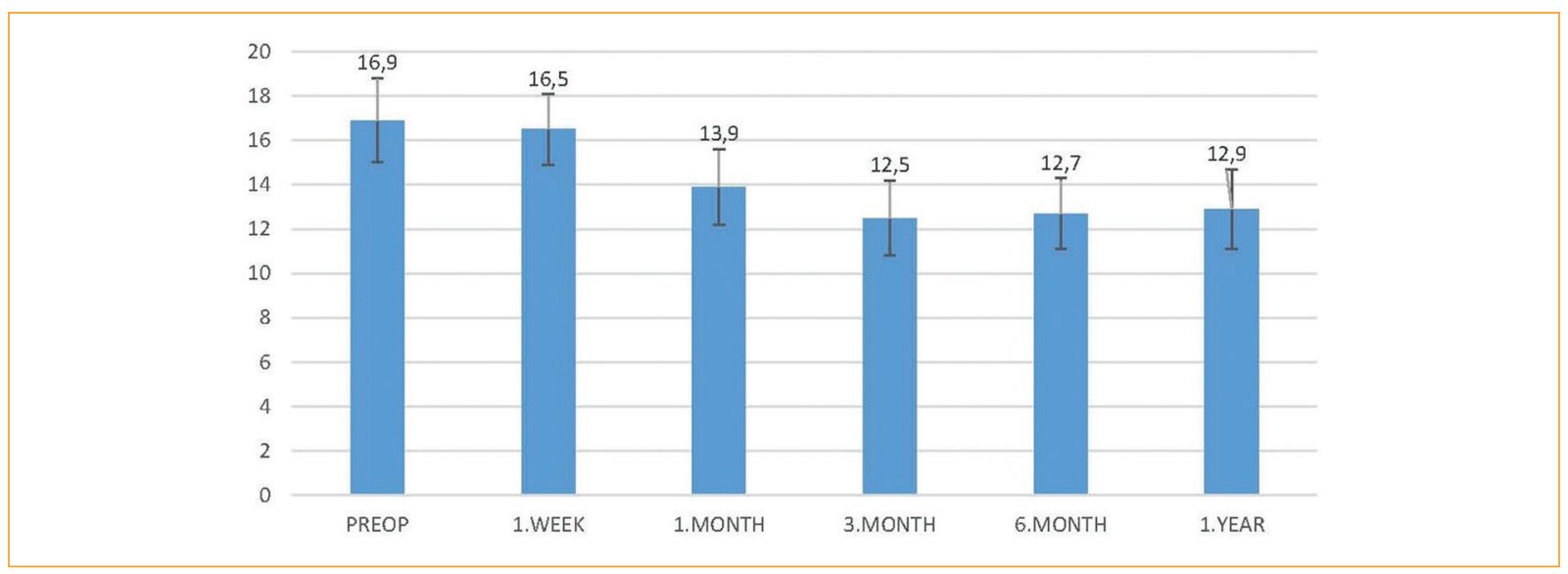

Figure 1. Intraocular pressure changes during follow-up.

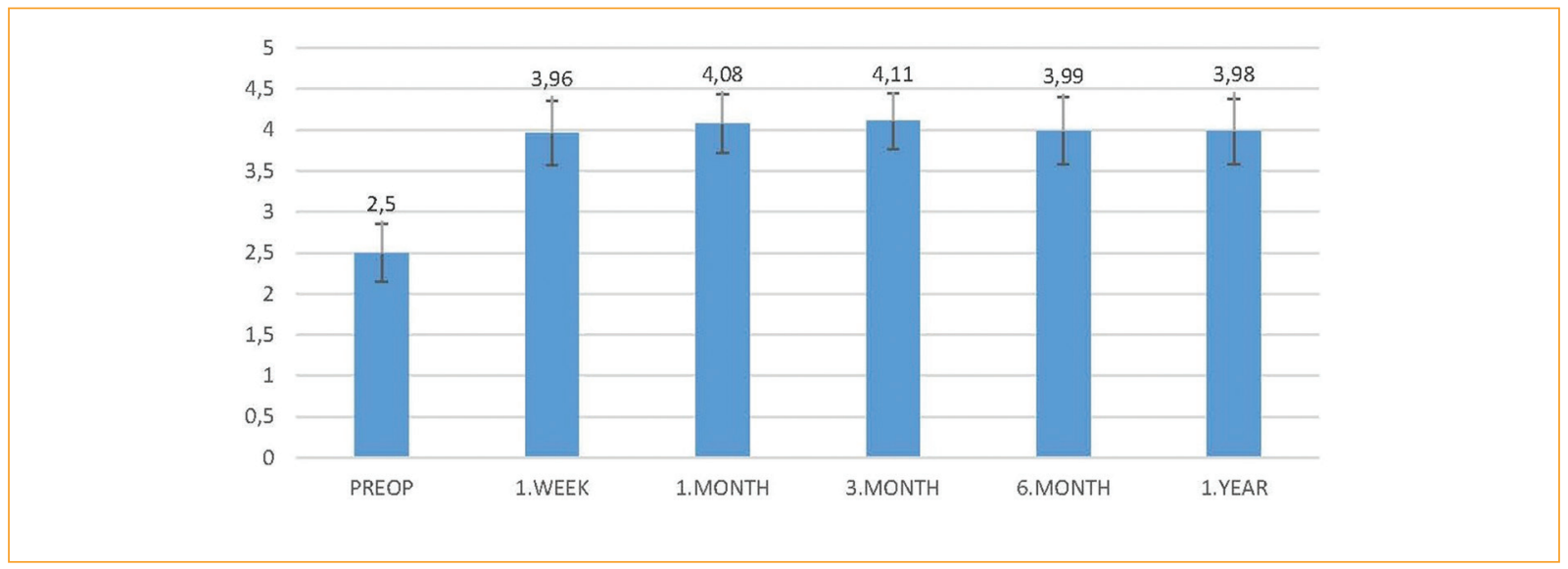

Figure 2. Anterior chamber depth changes during follow-up.

difference in IOP values at 3 months compared to 6 months and 1 year after phacoemulsification $(p>$ $0.05)(95 \% \mathrm{Cl}:-0.803-0.375$ and $-0.908-0.456$, respectively). The difference in IOP was also not significant when comparing the 6-month and 1-year time point $(p>0.05)(95 \% \mathrm{Cl}:-0.112$ to +0.024$)$.

ACD alterations before and after phacoemulsification is shown in table 1 and figure 2 . There was a statistically significant difference in the average ACD measurements between baseline and the post-operative week 1 , month 1 , month 3 , month 6 , and 1 year $(p<0.001)$ (95\% Cl: $-1.583-1.328,-1.693--1.459,-1.723 v-1.487$, $-1.653-1.391$, and $-1.603-1.353$, respectively). There was also a significant difference between week 1 and month 1 ACD measurements $(p=0.048) \quad(95 \%$ Cl: -0.197 to -0.044$)$, as well as the ACD dimensions measured at the $1^{\text {st }}$ week compared to the $3^{\text {rd }}$ month postoperatively ( $p=0.003)(95 \% \mathrm{Cl}:-0.238$ to -0.061$)$. However, no statistically significant difference was observed between week 1 and month 6 and year 1 ACD measurements after phacoemulsification $(p=0.494)$ (95\% Cl: $-0.119-+0.044$ and $-0.108-+0.065$, respectively). Similarly, the post-operative $1^{\text {st }}$-month and $3^{\text {rd }}$-month ACD dimensions did not significantly differ $(p>0.05)$ (95\% Cl: -0.085 to +0.026$)$. The difference between the $1^{\text {st }}$-month and $1^{\text {st }}$-year ACD measurements after surgery was statistically significant $(p<0.001)(95 \% \mathrm{Cl}$ : $0.026-$ 0.170 ). Another statistically significant difference was observed between the post-operative $3^{\text {rd }}$-month and $6^{\text {th }}$ month and $1^{\text {st }}$-year ACD dimensions $(p<0.001)(95 \%$ Cl: 0.011-0.198 and 0.069-0.185). Nevertheless, there was no significant difference between the $6^{\text {th }}$-month and $1^{\text {st }}$-year ACD measurement after surgery $(p>0.05)$ (95\% Cl: -0.188 to +0.074$)$. 


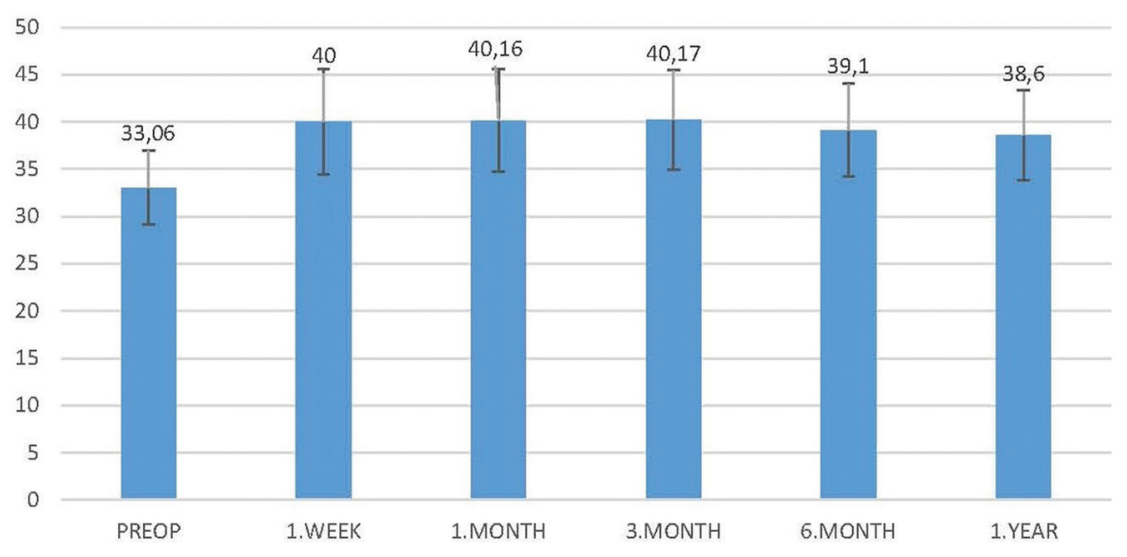

Figure 3. Anterior chamber angle changes during follow-up.

ACA alterations before and after surgery is presented in table 1 and figure 3 . There was a significant difference between the baseline and the post-operative $1^{\text {st }}$. week, $1^{\text {st }}$-month, $3^{\text {rd }}$-month, $6^{\text {th }}$-month, and $1^{\text {st }}$-year ACA values $(p<0.001)$ (95\% Cl: $-12.545-9.330$, $-12.784--9.410,-12.812--9.400,-12.411--8.847$, and -11.033--8.067, respectively). There was no significant difference between post-operative week 1 and 1 - and 3-month in terms of the ACA ( $p>0.05)(95 \% \mathrm{Cl}$ : $-1.062-$ +0.744 and $-1.176-+0.839$, respectively). A significant difference was observed in this parameter when week-1 measurement was compared to 6-month and 1-year measurements $(p=0.001)(95 \% \mathrm{Cl}: 0.359-1.839$ and 0.451-2.324, respectively). There was also a significant difference between values at 1 month and 6 months and 1 year after surgery $(p<0.001)(95 \% \mathrm{Cl}$ : $0.592-$ 1.998 and $0.704-2.390$, respectively), as well as between month 3 and month 6 and year $1(p<0.001)$ (95\% Cl: $0.764-2.248$ and 0.805-2.307, respectively). However, no significance was observed regarding ACA differences between the post-operative values at month 6 and year 1 ( $p>0.05)(95 \% \mathrm{Cl}:-0.485-+1.062)$.

ACV changes before and after surgery is shown in table 1 and figure 4 . There was a statistically significant difference between baseline and post-operative $1^{\text {st }}-$ week, $1^{\text {st }}$ month, $3^{\text {rd }}$-month, $6^{\text {th }}$-month, and $1^{\text {st }}$-year ACV measurements ( $p<0.001)(95 \% \mathrm{Cl}$ : -50.046--38.301, -54.320--42.415, -55.664--43.887, -53.844--41.427, and -51.631--38.899). There was also a significant difference between the mean post-operative $1^{\text {st }}$-week and the $1^{\text {st }}$ - and $3^{\text {rd }}$-month measurements $(p=0.002$ and $p<0.001$, respectively) (95\% Cl: $-7.504--0.883$ and $-8.601--2.603$, respectively). However, no significant difference was observed between week 1 and month 6 and year 1 measurement after surgery $(p>0.05)(95 \% \mathrm{Cl}:-3.876-+1.145$ and $-4.701-$ +2.517 , respectively). There was also no significant difference between the $1^{\text {st }}$-month and the $3^{\text {rd }}$-month ACV values $(p=0.608)(95 \% \mathrm{Cl}:-3.239-+0.423)$. A significant difference was observed between the $1^{\text {st }}$-month and the $6^{\text {th }}$ month and $1^{\text {st }}$-year ACV measurements after surgery $(p=$ $0.001)(95 \% \mathrm{Cl}: 0.626-4.497$ and $0.815-5.389$, respectively), as well as between the post-operative $3^{\text {rd }}$ month and the post-operative $6^{\text {th }}$ month and $1^{\text {st }}$ year $(p<0.001)(95 \%$ Cl: 1.867-5.979 and 2.493-6.528, respectively). There was no significant difference between post-operative ACV values on month 6 and year 1 measurements $(p>0.05)(95 \%$ Cl: $-2.859-+4.864)$.

CCT alterations before and after surgery is shown in table 1 and figure 5 . There was a statistically significant difference between baseline and post-operative $1^{\text {st }}$-week, $1^{\text {st }}$-month, and $3^{\text {rd }}$-month CCT measurements $(p<0.001)(95 \%$ Cl: -39.247--25.834, -11.878--4.530 and $-8.971--1.233$, respectively). There was no statistically significant difference between baseline and post-operative $6^{\text {th }}$-month and $1^{\text {st }}$-year CCT measurements $(p>0.05)(95 \% \mathrm{Cl}:-6.578-+0.547$ and $-4.343-$ +3.159 , respectively). A significant difference was detected between the $1^{\text {st }}$-week and the $1^{\text {st }}$-month, $3^{\text {rd }}$ month, $6^{\text {th }}$-month, and $1^{\text {st }}$-year measurements $(p<0.001)$ (95\% Cl: 18.430-30.243, 21.552-33.326, 23.674-36.778, and 25.783-38.115, respectively). However, no statistically significant difference was observed between the post-operative $1^{\text {st }}$ - and $3^{\text {rd }}$-month values after surgery ( $p>0.05)(95 \% \mathrm{Cl}:-2.774-+3.684)$. CCT measured at the post-operative $1^{\text {st }}$ month significantly differed compared to the post-operative $6^{\text {th }}$-month and $1^{\text {st }}$-year measurements $(p<0.001)(95 \% \mathrm{Cl}: 2.498-7.978$ and 4.864-10.361, respectively). There was also a significant 


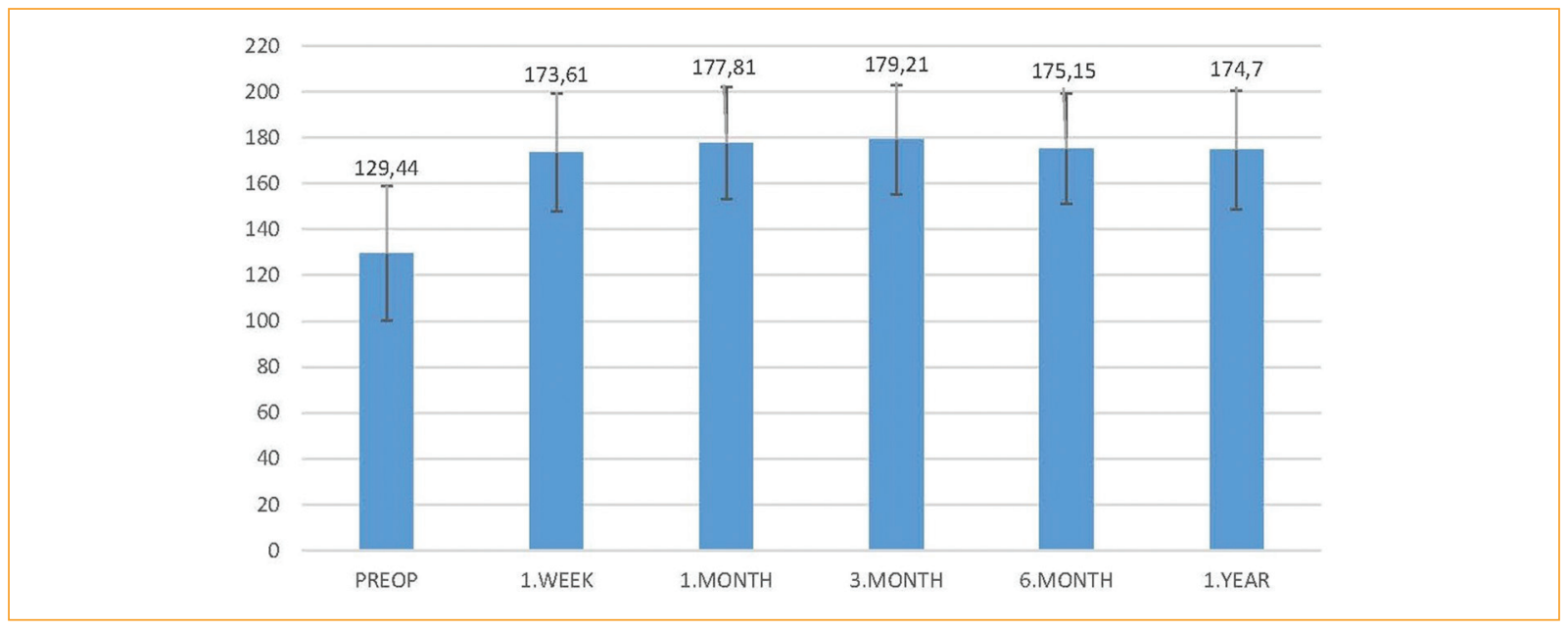

Figure 4. Anterior chamber volume changes during follow-up.

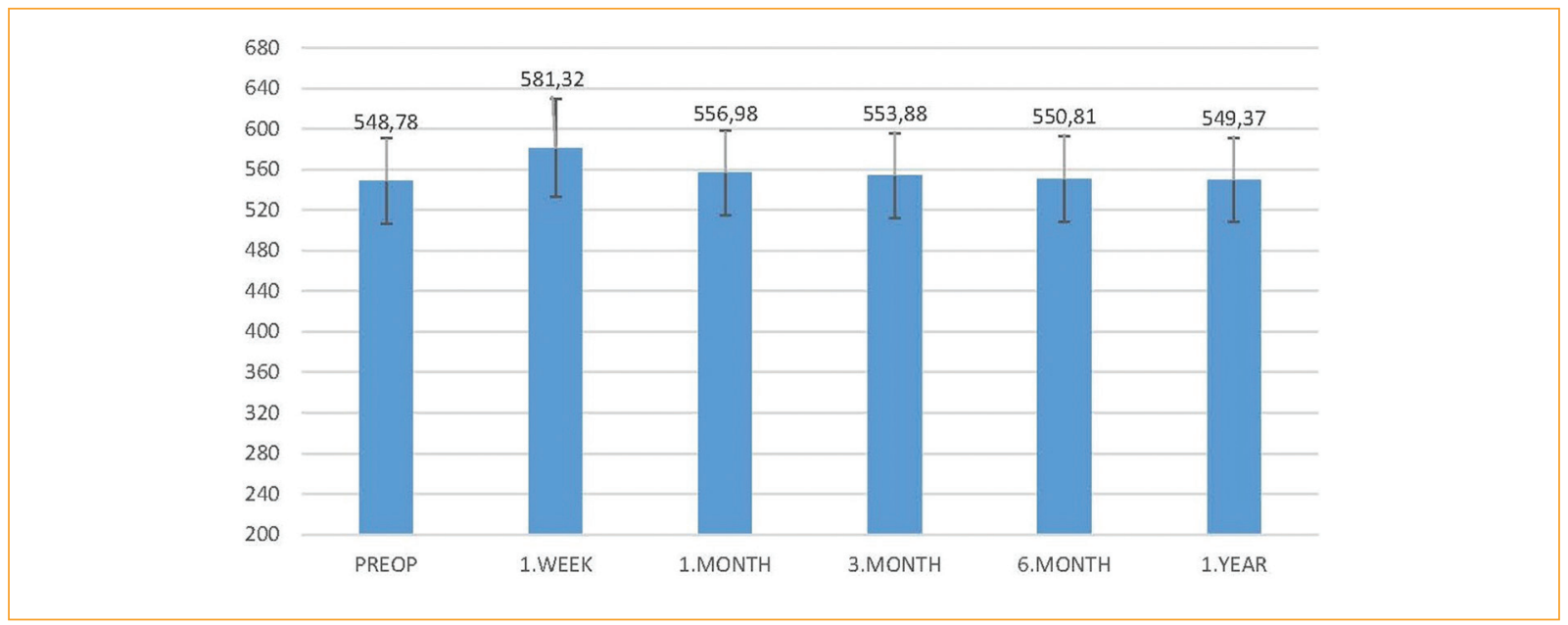

Figure 5. Central corneal thickness changes during follow-up.

difference when the post-operative $3^{\text {rd }}$-month CCT value was compared to the post-operative $6^{\text {th }}$-month and $1^{\text {st }}$-year values $(p<0.001)(95 \% \mathrm{Cl}: 1.984-4.763$ and 2.542-6.478, respectively). Nevertheless, the difference between the post-operative $6^{\text {th }}$-month and $1^{\text {st }}$-year values did not significantly differ $(p>0.05)(95 \%$ Cl: -3.084 to +4.258$)$.

\section{Discussion}

This study aimed to evaluate the effects of phacoemulsification on IOP and anterior segment parameters. In the literature, Yang et al. examined the changes in IOP after cataract surgery and found that IOP levels significantly decreased after a 3-month follow-up ${ }^{18}$. In our study, there was no statistically significant difference between baseline and post-operative $1^{\text {st }}$-week IOP measurements in the patients included in the study. However, mean IOP values were significantly lower 1 month after cataract surgery compared to pre-operative and post-operative 1-week values. Kashiwagi et al. showed that IOP values decrease postoperatively and that the reduction in IOP is significantly higher in eyes with a shallow pre-operative $\mathrm{ACD}^{22}$.

Chen et al., who investigated ACD alterations after phacoemulsification, reported that the post-operative $1^{\text {st }}$-day, $1^{\text {st }}$-week, and $1^{\text {st }}$-month ACD measurements were significantly higher compared to those of the pre-operative period, and ACD began to stabilize at the $1^{\text {st }}$-week visit after surgery ${ }^{23}$. In our prospective study, 
ACD continued to increase until 3 months after cataract surgery, and it was observed that ACD stabilized 6 months postoperatively.

Lee et al. examined the anterior segment biometric parameters after cataract surgery and found that ACA at the $3^{\text {rd }}$-month follow-up was significantly higher compared to baseline ${ }^{24}$. Altan et al. evaluated ACD, IOP, and ACA changes after uneventful phacoemulsification and reported similar results such as reduced IOP values and increased $A C D$ and $A C A^{25}$. In the current study, ACA increased after cataract surgery and remained stable between 1 week and 3 months after surgery. ACA was slightly reduced 6 months after cataract surgery, but it was still wider compared to pre-operative values. We observed that ACA values stabilized 6 months after cataract surgery.

Concerning ACV measurements, the $1^{\text {st }}$-week value was significantly higher than the baseline. The increase in ACV continued at the $1^{\text {st }}$-month visit after surgery. However, mean $6^{\text {th }}$-month and $1^{\text {st }}$-year ACV values after cataract surgery, almost returned to week 1 levels. On the other hand, post-operative $6^{\text {th }}$-month and $1^{\text {st }}$-year ACV measurements were significantly higher compared to mean baseline value, and significantly lower compared to post-operative $1^{\text {st }}$-month and $3^{\text {rd }}$-month measurements.

Cetinkaya et al. evaluated the effect of phacoemulsification surgery on IOP and anterior segment anatomy and found that ACD, IOP, and CCT values returned to pre-operative levels over the long-term follow-up after surgery ${ }^{14}$. In our study, CCT values also decreased to pre-operative levels at the $6^{\text {th }}$-month and $1^{\text {st }}$-year visits after surgery. This study showed that CCT stabilized 6 months after surgery.

\section{Conclusions}

This study showed that after phacoemulsification, IOP decreases in the short- and long-term follow-up compared to the pre-operative period. However, parameters such as the depth, angle, and volume of the anterior chamber increase in the short- and long-term follow-up after surgery. Although CCT increased in the early post-operative period, it returned to pre-operative levels in the long term.

\section{Conflicts of interest}

This study was not funded. In accordance with ethical obligation as researchers, all authors declare that they have no conflicts of interest concerning this research.

\section{Ethical disclosures}

Protection of human and animal subjects. The authors declare that no experiments were performed on humans or animals for this study.

Confidentiality of data. The authors declare that no patient data appear in this article.

Right to privacy and informed consent. The authors declare that no patient data appear in this article.

\section{References}

1. Kanski JJ, Bowling B. Lens. In: Nischal KK, Pearson A, editors. Clinical Ophtalmology a Systematic Approach. $7^{\text {th }}$ ed. Edinburgh: Elsevier/Saunders; 2011. p. 163-91.

2. Thompson J, Lakhani N. Cataracts. Prim Care. 2015;42:409-23.

3. Lee CM, Afshari NA. The global state of cataract blindness. Curr Opin Ophthalmol. 2017;28:98-103.

4. Chan WH, Biswas S, Ashworth JL, Lloyd IC. Congenital and infantile cataract: aetiology and management. Eur J Pediatr. 2012;171:625-30.

5. Lin $\mathrm{H}$, Lin D, Liu Z, Long E, Wu X, Cao Q, et al. Novel congenital cataract category system based on lens opacity locations and relevant anterior segment characteristics. Invest Ophthalmol Vis Sci. 2016;57: 6389-95.

6. Liu YC, Wilkins M, Kim T, Malyugin B, Mehta JS. Cataracts. Lancet. 2017;390:600-12.

7. Yanoff M. Indications for lens surgery and different techniques. In: Yanoff M, Duker JS, editors. Ophthalmology. $2^{\text {nd }}$ ed. St Louis: Mosby; 2004. p. 315-25

8. Solano MM, Lin SC. Cataract, phacoemulsification and intraocular pressure: is the anterior segment anatomy the missing piece of the puzzle? Prog Retin Eye Res. 2018:64:77-83.

9. Lee W, Bae HW, Kim CY, Seong GJ. The change of anterior segment parameters after cataract surgery in normal-tension glaucoma. Int $\mathrm{J}$ Ophthalmol. 2017;10:1239-45.

10. Rękas M, Barchan-Kucia K, Konopińska J, Mariak Z, Żarnowski T. Analysis and modeling of anatomical changes of the anterior segment of the eye after cataract surgery with consideration of different phenotypes of eye structure. Curr Eye Res. 2015;40:1018-27.

11. Sengupta S, Venkatesh R, Krishnamurthy $P$, Nath M, Mashruwala A, Ramulu PY, et al. Intraocular pressure reduction after phacoemulsification versus manual small-incision cataract surgery: a randomized controlled trial. Ophthalmology. 2016;123:1695-703.

12. Beato JN, Reis D, Esteves-Leandro J, Falcão M, Rosas V, Carneiro Â, et al. Intraocular pressure and anterior segment morphometry changes after uneventful phacoemulsification in Type 2 diabetic and nondiabetic patients. J Ophthalmol. 2019;2019:9390586.

13. Slabaugh MA, Bojikian KD, Moore DB, Chen PP. The effect of phacoemulsification on intraocular pressure in medically controlled openangle glaucoma patients. Am J Ophthalmol. 2014;157:2631

14. Cetinkaya S, Dadaci Z, Yener HI, Acir NO, Cetinkaya YF, Saglam F. The effect of phacoemulsification surgery on intraocular pressure and anterior segment anatomy of the patients with cataract and ocular hypertension. Indian J Ophthalmol. 2015;63:743-45.

15. Mansberger SL, Gordon MO, Jampel $H$, Bhorade A, Brandt JD, Wilson $\mathrm{B}$, et al. Reduction in intraocular pressure after cataract extraction: the ocular hypertension treatment study. Ophthalmology. 2012; 119:182631.

16. Huang G, Gonzalez E, Peng PH, Lee R, Leeungurasatien T, He M, et al. Anterior chamber depth, iridocorneal angle width and intraocular pressure changes after phacoemulsification: narrow vs open iridocorneal angles. Arch Ophthalmol. 2011;129:1283-90.

17. Huang G, Gonzalez E, Lee R, Chen YC, He M, Lin SC. Association of biometric factors with anterior chamber angle widening and intraocular pressure reduction after uneventful phacoemulsification for cataract. $J$ Cataract Refract Surg. 2012;38:108-16.

18. Yang HS, Lee J, Choi S. Ocular biometric parameters associated with intraocular pressure reduction after cataract surgery in normal eyes. Am J Ophthalmol. 2013;156:89-94.

19. Shrivastava A, Singh K. The effect of cataract extraction on intraocular pressure. Curr Opin Ophthalmol. 2010;21:11822.

20. Ucakhan OO, Ozkan M, Kanpolat A. Anterior chamber parameters measured by the pentacam CES after uneventful phacoemulsification in normotensive eyes. Acta Ophthalmol. 2009;87:544-48. 
A. Ugurlu, N. Gamze-Tasli: Anterior segment changes after phacoemulsification

21. Issa SA, Pacheco J, Mahmood U, Nolan J, Beatty S. A novel index for predicting intraocular pressure reduction following cataract surgery. $\mathrm{Br} \mathrm{J}$ Ophthalmol. 2005;89:543-46.

22. Kashiwagi K, Kashiwagi F, Tsukahara S. Effects of small-incision phacoemulsification and intraocular lens implantation on anterior chamber depth and intraocular pressure. J Glaucoma. 2006;15:103-9.

23. Chen M, Hu H, He W, Lu Y, Zhu X. Observation of anterior chamber volume after cataract surgery with swept-source optical coherence tomography. Int Ophthalmol. 2019;39:1837-44.
24. Lee RY, Kasuga T, Cui QN, Huang G, Wang SY, Lin SC. Ethnic differences in intraocular pressure reduction and changes in anterior segment biometric parameters following cataract surgery by phacoemulsification. Clin Exp Ophthalmol. 2013:41:442-9.

25. Altan C, Bayraktar S, Altan T, Eren H, Yilmaz OF. Anterior chamber depth, iridocorneal angle width, and intraocular pressure changes after uneventful phacoemulsification in eyes without glaucoma and with open iridocorneal angles. J Cataract Refract Surg. 2004;30: 832-8. 